\title{
ARTICLE \\ Dynorphin-kappa opioid receptor activity in the central amygdala modulates binge-like alcohol drinking in mice
}

\author{
Rachel I. Anderson ${ }^{1}$, Marcelo F. Lopez ${ }^{1}$, William C. Griffin ${ }^{1}$, Harold L. Haun ${ }^{2}$, Daniel W. Bloodgood ${ }^{3,4}$, Dipanwita Pati $\mathbb{i D}^{4}$, Kristen M. Boyt ${ }^{4}$, \\ Thomas L. Kash $\left(\mathbb{D}^{3,4}\right.$ and Howard C. Becker ${ }^{1,2,5}$
}

\begin{abstract}
Although previous research has demonstrated a role for kappa opioid receptor-mediated signaling in escalated alcohol consumption associated with dependence and stress exposure, involvement of the dynorphin/kappa opioid receptor (DYN/KOR) system in binge-like drinking has not been fully explored. Here we used pharmacological and chemogenetic approaches to examine the influence of DYN/KOR signaling on alcohol consumption in the drinking-in-the-dark (DID) model of binge-like drinking. Systemic administration of the KOR agonist U50,488 increased binge-like drinking (Experiment 1) while, conversely, systemic administration of the KOR antagonist nor-BNI reduced drinking in the DID model (Experiment 2). These effects of systemic KOR manipulation were selective for alcohol as neither drug influenced consumption of sucrose in the DID paradigm (Experiment 3). In Experiment 4, administration of the long-acting KOR antagonist nor-BNI into the central nucleus of the amygdala (CeA) decreased alcohol intake. Next, targeted "silencing" of DYN+ neurons in the CeA was accomplished using a chemogenetic strategy. Cre-dependent viral expression in DYN+ neurons was confirmed in CeA of Pdyn-IRES-Cre mice and functionality of an inhibitory (hM4Di) DREADD was validated (Experiment 5). Activating the inhibitory DREADD by CNO injection reduced binge-like alcohol drinking, but CNO injection did not alter alcohol intake in mice that were treated with control virus (Experiment 6). Collectively, these results demonstrate that DYN/KOR signaling in the CeA contributes to excessive alcohol consumption in a binge-drinking model.
\end{abstract}

Neuropsychopharmacology (2019) 44:1084-1092; https://doi.org/10.1038/s41386-018-0294-3

\section{INTRODUCTION}

Binge drinking is a common pattern of alcohol intake in the U.S. and results in numerous negative behavioral, social, and medicalrelated consequences [1]. Binge drinking is defined as a pattern of drinking wherein alcohol consumption over a relatively short period of time results in rapid elevation of blood alcohol concentrations (BACs) above $0.08 \%(80 \mathrm{mg} / \mathrm{dL})$ [2]. While not all individuals that drink in a binge-like manner are alcohol dependent, binge drinking has been shown to be an important factor in the progression of addiction and increased risk for developing alcohol use disorder [3, 4]. Indeed, intoxication resulting from binge drinking has been viewed as an integral component of the alcohol addiction cycle $[5,6]$. Thus, in order to develop more effective treatment interventions that impede transition to heavy uncontrolled compulsive-like drinking, it is important to understand mechanisms that promote and mediate motivation to engage in binge patterns of alcohol consumption.

A common model used for studying the neurobiological mechanisms underlying binge drinking involves offering mice the opportunity to drink alcohol in the home cage for a restricted period of time during the dark phase of their circadian cycle. As originally described by Crabbe and colleagues [7, 8], this "drinkingin-the-dark" (DID) model has been shown to reliably generate high levels of alcohol intake with corresponding BACs reaching $>80$ $\mathrm{mg} / \mathrm{dL}[9,10]$. Such binge-like consumption is most readily observed in mice genetically predisposed to consume alcohol (e.g., C57BL/6 J strain) [11] or mice selectively bred to drink in a manner that achieves high BACs in a relatively short period of time [12].

Numerous studies have employed the DID model to examine neurobiological mechanisms underlying binge-like alcohol consumption [13]. A major focus of this work has been on various neuropeptide systems, including CRF [14-16], NPY [17, 18], orexin $[19,20]$, and oxytocin [21]. Interestingly, a role for the endogenous opioid neuropeptide dynorphin (DYN) in binge-like drinking has not been investigated, although its regulation of alcohol consumption in the context of dependence has recently gained attention.

DYNs preferentially bind to kappa opioid receptors (KOR), and both the peptide and receptor are widely distributed throughout the brain [22-24]. The overlapping expression of DYN and KOR with reward and stress pathways contributes to the ability of this neuropeptide system to alter stress- and reward-related signaling in the brain [25-27]. Activation of KOR generally produce aversive and dysphoric effects, and numerous studies have shown DYN/ KOR activity to play a role in mediating negative affective/

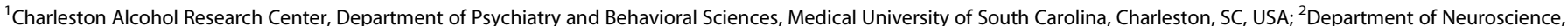

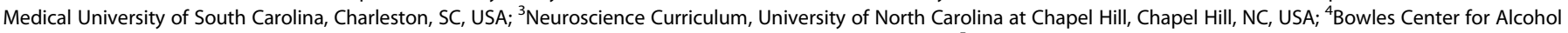

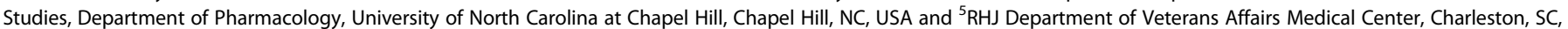
USA

Correspondence: Howard C. Becker (beckerh@musc.edu)

Received: 19 June 2018 Revised: 19 November 2018 Accepted: 21 November 2018

Published online: 11 December 2018 
dysphoric effects associated with chronic alcohol exposure and withdrawal, as well as the interaction of stress with alcohol [22, 24, 26]. Pharmacological manipulation of KOR has been shown to modulate alcohol consumption under a variety of circumstances. In particular, increased KOR signaling has been implicated in dependence-related escalated drinking [28-32], as well as stress enhancement of alcohol consumption [33-36]. Despite a growing body of literature indicating a significant role for the DYN/KOR system in alcohol addiction, few studies have examined the role of the DYN/KOR system in binge-like alcohol drinking. The present study was designed to address this issue.

Here we demonstrate that systemic administration of a KOR agonist increases binge-like alcohol drinking while treatment with KOR antagonists reduces alcohol consumption in the DID model. Direct injection of a KOR antagonist into the central nucleus of the amygdala $(\mathrm{CeA})$ decreased drinking in the DID model, implicating a role for DYN/KOR activity within the CeA. Using a targeted chemogenetic approach, selective inhibition of DYN-containing neurons in the CeA significantly reduced alcohol drinking in the model as well. Collectively, these results indicate that DYN/KOR activity play a significant role in regulating binge-like alcohol consumption, and this effect is mediated, at least in part, by DYN transmission and KOR signaling in the CeA.

\section{MATERIALS AND METHODS}

Subjects

Adult male C57BL/6 J mice (Jackson Laboratories, Bar Harbor, $\mathrm{ME})$ or adult male Cre + mice from an in-house colony of prodynorphin (Pdyn)-IRES-Cre mice [37] were used. Animals (10-14 weeks old) were housed and tested in a temperature and humidity controlled AAALAC approved facility with food and water continuously available. All mice were individually housed under a reverse $12 \mathrm{~h}$ light/dark cycle and acclimated to the facility at least one week prior to the start of experimentation. At all times, mice were treated in accordance with the NIH Guide for the Care and Use of Laboratory Animals (National Research Council, 2011), as well as the Institutional Animal Care and Use Committee at MUSC and UNC.

Alcohol binge-drinking procedure

Binge-like alcohol consumption was determined by using the DID paradigm [8]. Each drinking cycle consisted of 4 days of alcohol access followed by 3 days off prior to the next cycle. On days 1-3, water bottles were replaced with one bottle containing alcohol ( $20 \% \mathrm{v} / \mathrm{v}$ ethanol), with the 2 -hr drinking sessions starting $3 \mathrm{~h}$ into the dark cycle. On Day 4 of each DID cycle, access to alcohol was extended to $4 \mathrm{~h}$ (alcohol intake was measured at both 2-hr and 4$\mathrm{hr}$ time points). An identical procedure was used for assessment of $0.5 \%$ sucrose $(w / v)$ consumption. Drug testing or chemogenetic manipulation occurred prior to the Day 4 drinking sessions.

\section{Drugs and administration}

The KOR agonist U50,488 and the KOR antagonist norBinalorphimine dihydrochloride (nor-BNI) (Tocris) were dissolved in saline. The short-acting KOR antagonist LY2444296 (also known as compound 25 in [38] and FP3FBZ in [39]), was generously provided by Eli Lilly and was dissolved in a 3\% Tween-80 solution $(w / v)$. Clozapine-N-oxide (CNO; Tocris) was dissolved in saline. Systemic administration of U50,488 $(5 \mathrm{mg} / \mathrm{kg})$, nor-BNI $(10 \mathrm{mg} / \mathrm{kg})$, LY2444296 (5 mg/kg), and CNO (3 mg/kg) was delivered via intraperitoneal (ip.) injection $(10 \mathrm{ml} / \mathrm{kg})$. Doses of U50,488, nor$\mathrm{BNI}$, and LY2444296 were based on preliminary studies described in the Supplementary Material. For direct brain infusion, the longacting KOR antagonist nor-BNI was dissolved in PBS $(5 \mu \mathrm{g} / \mu \mathrm{l})$ and bilaterally microinjected $(0.5 \mu$ lover $2 \mathrm{~min})$ into the central nucleus of the amygdala (CeA) to achieve a dose of $5 \mu \mathrm{g}(2.5 \mu \mathrm{g} / \mathrm{side})$. Injectors were left in place for an additional 2 min before removal.
Surgical procedures

C57BL/6 J mice were anesthetized with isoflurane and implanted with dual guide cannulae (Plastics One) aimed at the central nucleus of the amygdala (AP $-1.22, \mathrm{ML}+/-3.0$, DV -4.1 ). When inserted, microinjector tips extended $0.5 \mathrm{~mm}$ beyond the guide. Viral constructs (AAV5-hSyn-DIO-hM4D-mCherry and AAV8-hSynDIO-mCherry) were obtained from the UNC Vector Core and were bilaterally infused $(0.25 \mu \mathrm{l}$ delivered over $5 \mathrm{~min}$ for each side) into the CeA of Pdyn-IRES-Cre mice (AP $-1.22, \mathrm{ML}+/-3.00$, DV $-4.60)$. Microinjectors for virus delivery were left in place for 5 $\mathrm{min}$, and then gradually removed over an additional $5 \mathrm{~min}$.

Experimental procedures

Experiment 1. Effect of KOR activation on binge-like alcohol drinking. $\mathrm{C} 57 \mathrm{BL} / 6 \mathrm{~J}$ mice were injected with the KOR agonist U50,488 $(5 \mathrm{mg} / \mathrm{kg})(N=14)$ or saline $(N=13) 30 \mathrm{~min}$ prior to the start of the $4 \mathrm{hr}$ test drinking session of the DID procedure. The dose and timing of administration were based on our previous work [33]. Blood samples were collected immediately after the session to assess BAC using an AM1 Alcohol Analyzer (Analox Instruments, Stourbridge, UK).

Experiment 2. Effect of KOR blockade on binge-like alcohol drinking. C57BL/6 J mice were injected with the KOR antagonist nor-BNI (10 $\mathrm{mg} / \mathrm{kg}$ ) or saline ( $N=10 /$ group) $2 \mathrm{hr}$ following the Day-3 drinking session ( $22 \mathrm{hr}$ prior to the $4 \mathrm{hr}$ test drinking session). The dose and timing of administration were based on our findings (see Supplemental Data) and other published work [30, 36]. In a separate study, the short-acting KOR antagonist LY2444296 $(5 \mathrm{mg} / \mathrm{kg})(N=18)$ or saline $(N=16)$ were injected $30 \mathrm{~min}$ prior to the start of the $4 \mathrm{hr}$ test drinking session. The dose and timing of LY2444296 administration were based on our previous work [33]. Blood samples were collected immediately after the test sessions for BAC measurement.

Experiment 3. Effect of KOR activation or blockade on sucrose consumption. To assess selectivity of systemic KOR agonist and antagonist effects, C57BL/6 J mice were subjected to the DID procedure with $0.5 \%$ sucrose instead of alcohol. Separate groups of mice were tested with the KOR agonist U50,488 $(0$ or $5 \mathrm{mg} / \mathrm{kg}$; $N=5-6 /$ group) or the KOR antagonist nor-BNI ( 0 or $10 \mathrm{mg} / \mathrm{kg} ; N$ $=10 /$ group). Additionally, LY2444296 ( 0 or $5 \mathrm{mg} / \mathrm{kg} ; N=6 /$ group) was evaluated in this sucrose test. Drug doses and timing of administration were the same as in Experiments 1 and 2 .

Experiment 4. Effect of intra-CeA injection of a KOR antagonist on binge-like alcohol drinking. Following recovery from stereotaxic surgery (minimum of one week), C57BL/6 J mice consumed alcohol in the DID procedure over several weekly cycles. Each 4day weekly cycle (Monday-Thursday) consisted of three consecutive days of $2 \mathrm{hr}$ access and then $4 \mathrm{hr}$ access on Day 4 . Mice were handled daily to acclimate them to the microinjection procedure. At $2 \mathrm{~h}$ following the third day of the fifth DID cycle ( 20 $\mathrm{h}$ prior to the start of the Day 4 test session), mice received bilateral infusion of nor-BNI $(2.5 \mu \mathrm{g} / \mathrm{side})(N=10)$ or vehicle (PBS) $(N=9)$. Immediately following the 4 -hr test session, blood samples were collected for BAC analysis.

Experiment 5. Genetic targeting for selective chemogenetic inactivation of DYN-containing neurons

Adult male Pdyn-IRES-Cre mice were either sacrificed for in situ hybridization $(N=4)$ or infused with a virus containing Designer Receptors Exclusively Activated by Designer Drugs (DREADDs) [40] targeting the $\mathrm{CeA}(N=6)$. Mice were anesthetized with isoflurane and rapidly decapitated. Brains were dissected and flash frozen on dry ice for $15 \mathrm{~min}$ and stored at $-80^{\circ} \mathrm{C}$ until sectioned for in situ hybridization (ISH). Brain slices $(16 \mu \mathrm{m})$ containing the CeA were obtained utilizing a Leica CM 3050S cryostat (Leica Biosystems, Nussloch, Germany) at $-20^{\circ} \mathrm{C}$ and were mounted directly onto 
1086

microscope slides. Slides containing ISH sections were stored at $-80^{\circ} \mathrm{C}$ until processed for ISH and analyzed for PDYN + and Cre

+ cell counts (see Supplemental Methods).

Mice that received viral infusions of an inhibitory (Gi/o) DREADD (AAV8-hSyn-DIO-hM4Di-mCherry) targeting the CeA were anesthetized with isoflurane and rapidly decapitated three weeks following surgery. Brains were quickly removed, sectioned coronally on a vibratome, and prepared for electrophysiological recordings. DREADD-expressing neurons were visually identified in the $\mathrm{CeA}$ via mCherry fluorescence. Intrinsic neuronal excitability measures were performed before and after bath application of CNO $(10 \mu \mathrm{M})$ (see Supplemental Methods).

Experiment 6. Effect of chemogenetic inactivation of DYN-containing neurons in $\mathrm{CeA}$ on binge-like alcohol drinking. Adult male PdynIRES-Cre mice were infused with a virus containing an inhibitory DREADD (AAV-hSyn-DIO-hM4Di-mCherry) $(N=9)$ or control virus (AAV-hSyn-DIO-mCherry) $(N=9)$ targeting the CeA. Subjects were left undisturbed for three weeks to allow for viral infection prior to the start of weekly DID cycles. At $30 \mathrm{~min}$ prior to the 4 -hr test sessions during two consecutive weekly DID cycles, mice were injected with vehicle (saline) and CNO ( $3 \mathrm{mg} / \mathrm{kg}$ ). A within-subjects crossover design was used, with order of drug treatment (saline vs. $\mathrm{CNO}$ ) counter-balanced across the two test sessions. During a subsequent DID cycle, all mice were pretreated with U50,488 (5 $\mathrm{mg} / \mathrm{kg}) 15 \mathrm{~min}$ prior to injection of CNO $(3 \mathrm{mg} / \mathrm{kg})$, which was again given 30 min before the 4-hr drinking test session.

\section{Histology}

At the conclusion of Experiments 4 and 6, the mice were euthanized and brains were histologically examined for injector placement (Experiment 4) or viral expression (Experiment 6). Details of histological procedures are provided in Supplemental Materials.

\section{Statistical analyses}

Alcohol intake $(\mathrm{g} / \mathrm{kg})$ at 2-hr and 4-hr time points during the Day 4 test sessions in Experiments 1 and 2 were analyzed by 2-way ANOVAs, with Dose as a between-subjects factor and Time as a repeated measure. Similar analyses (Drug $\times$ Time) were performed for 2-hr alcohol intake across the four days of the DID procedure and cumulative intake over the 4-hr test sessions was analyzed by $t$-tests for each of the drugs (data presented in Supplemental Material). BAC $(\mathrm{mg} / \mathrm{dL})$ data were analyzed by $t$-tests. Sucrose intake $(\mathrm{ml} / \mathrm{kg})$ data in Experiment 3 (4-hr test session) were analyzed by separate $t$ tests for U50,488, nor-BNI, and LY2444296 treatments. In Experiment 4, alcohol intake over the 4-hr Day 4 test session and BAC data were analyzed by $t$-tests. In Experiment 5 , change in the resting membrane potential was analyzed with a one-sample $t$-test. Changes in the rheobase following drug (CNO) application was measured within the same cells using a paired two-sample $t$-test. In Experiment 6, alcohol intake during the Day-4 test sessions were analyzed separately in mice that received injections of inhibitory DREADD virus or control virus by ANOVA, with Drug (saline vs. CNO) and Time ( $2 \mathrm{hr}$ vs. $4 \mathrm{hr}$ ) as repeated measures. These data were also analyzed by ANOVA with order of testing included as an additional factor. The effect of U50,488 pretreatment was analyzed by 2-way ANOVA, with Treatment (saline, CNO, and CNO + U50,488) and Time as repeated factors. Statistical analyses were carried out using Statistica (TIBCO) software package. Post-hoc comparisons were performed when appropriate (Newman-Keuls), and significance level for all analyses was $p<0.05$.

\section{RESULTS}

Experiment 1: Systemic administration of a KOR agonist increases binge-like alcohol drinking

Analysis of alcohol intake during the Day 4 test session indicated a significant main effect of Time $[F(1,25)=120.98, p<0.001]$, with intake being greater at $4 \mathrm{hr}$ compared to $2 \mathrm{hr}$. ANOVA also revealed a significant main effect of Dose $[F(1,25)=31.94, p<$ $0.001]$, but the Dose $\times$ Time interaction was not significant $[F(1,25)$ $=0.21, p>0.50]$. This indicates that systemic administration of the KOR agonist U50,488 (5 mg/ $/ \mathrm{kg})$ significantly increased alcohol consumption compared to mice that received saline, and this effect was similar at 2-hr and 4-hr time points (Fig. 1a). The increase in alcohol intake produced by the KOR agonist resulted in elevated BAC, an effect that fell just short of statistical significance $[t(24)=2.00, p=0.056]$ (Fig. 1b).

Experiment 2: Systemic administration of a KOR antagonist reduces binge-like alcohol drinking

As expected, alcohol intake was greater at $4 \mathrm{hr}$ compared to $2 \mathrm{hr}$ during the Day 4 test session. This was supported by a significant main effect of Time $[F(1,18)=64.79, p<0.001]$. ANOVA also revealed a significant main effect of Dose $[F(1,18)=8.20, p<$ 0.01], reflecting significantly reduced alcohol intake in mice treated with nor-BNI $(10 \mathrm{mg} / \mathrm{kg})$ compared to vehicle. The lack of a significant Dose $\times$ Time interaction $[F(1,18)=0.14, p>0.25]$ indicates that the KOR antagonist decreased alcohol consumption to a similar extent at $2 \mathrm{hr}$ and $4 \mathrm{hr}$ time points (Fig. 1c). Reduced alcohol intake produced by the KOR antagonist resulted in significantly lower $B A C$ registered immediately following the test session $[t(18)=2.49, p<0.05$ ] (Fig. 1d). Similar results (reduced alcohol intake and BAC) were obtained with the short-acting KOR antagonist LY2444296 (see Supplemental Data).

Experiment 3: KOR activation or blockade does not alter sucrose consumption

Neither systemic administration of the KOR agonist U50,488 (5 $\mathrm{mg} / \mathrm{kg}$ ) (Fig. 2a) nor the KOR antagonist nor-BNI $(10 \mathrm{mg} / \mathrm{kg})$ (Fig. 2b) significantly altered sucrose intake during the test session $[t(9)=0.45, p>0.10]$ and $[t(18)=2.05, p>0.05]$, respectively. A similar outcome was observed following administration of LY2444296 (see Supplemental Data).

Experiment 4: Intra-CeA injection of a KOR antagonist reduces binge-like alcohol drinking

Histological evaluation indicated incorrect microinjector placement for two mice that were injected with PBS and two mice that were injected with the KOR antagonist nor-BNI. Data from these mice were excluded in all analyses. Also, a blood sample from one of the subjects that received nor-BNI treatment was not assayed due to an experimental error. Microinjection of norBNI $(5 \mu \mathrm{g})$ into the CeA significantly reduced alcohol consumption during the Day 4 test session compared to mice that received intra-CeA injection of PBS $[t(13)=2.35, p<0.05]$ (Fig. 3a). The decrease in alcohol intake produced significantly lower BAC immediately following the $4 \mathrm{hr}$ test session $[t(12)=$ 2.41, $p<0.05$ ] (Fig. 3b).

Experiment 5: Genetic targeting for selective chemogenetic inactivation of DYN-containing neurons

Because our pharmacological data in Experiment 4 demonstrated that KOR blockade in the $\mathrm{CeA}$ decreases binge-like drinking, we next tested whether "silencing" dynorphinergic neurons in the CeA similarly influences alcohol intake. To validate our targeted approach, we first evaluated the fidelity of Cre expression in DYNcontaining $\mathrm{CeA}$ neurons in Pdyn-IRES-Cre mice. Using in situ hybridization, we observed a high degree of colocalization between Pdyn and Cre expressing neurons (Fig. 4a). The observed counts showed good penetrance of DYN expressing population, $M=80.2 \%$, as well as a high degree of fidelity, $M=94.0 \%$ (Fig. $4 \mathrm{~b}$ ).

Next, we tested the functionality of the inhibitory DREADD used in our behavioral studies. Three weeks following stereotaxic injection of a virus containing an inhibitory DREADD (AAV8-DIOhM4Di-mCherry) into the CeA, acute brain sections were prepared 

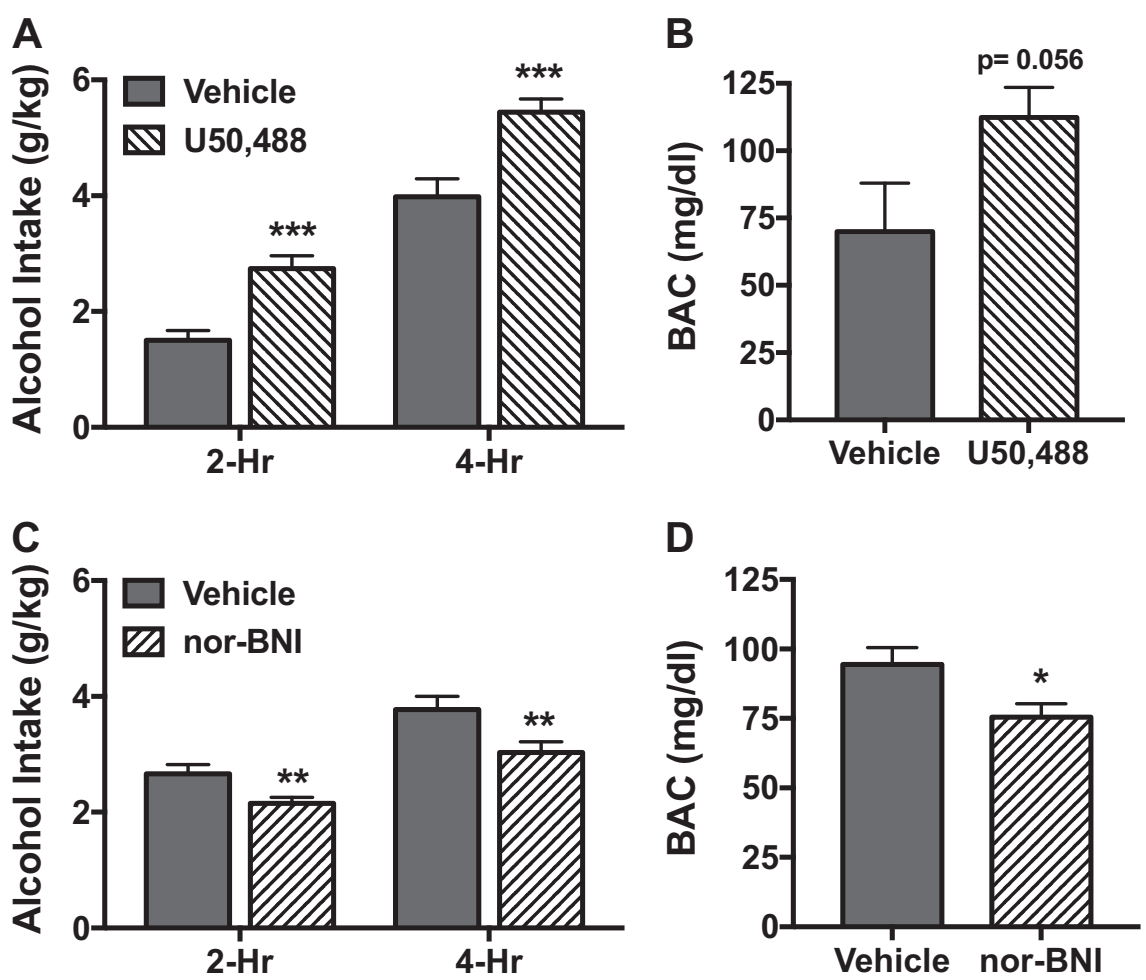

Fig. 1 Systemic administration of U50,488 increases while nor-BNI decreases binge-like alcohol consumption. a Mice received injection (ip.) of vehicle (saline) $(N=13)$ or U50,488 $(5 \mathrm{mg} / \mathrm{kg})(N=14) 30 \mathrm{~min}$ prior to the start of the 4-hr test drinking session of the DID procedure. U50,488 treatment significantly increased alcohol consumption at both 2-hr and 4-hr time points ( $\left.{ }^{* * *} p<0.001\right)$. b Increased drinking following U50,488 treatment resulted in a trend for elevated blood alcohol concentrations $(p=0.056)$. c Mice received injection (ip.) of vehicle (saline) $(N=10)$ or nor-BNI $(10 \mathrm{mg} / \mathrm{kg})(N=10) 2 \mathrm{~h}$ after the Day 3 session $(22 \mathrm{hr}$ prior to the start of the $4 \mathrm{hr}$ (Day-4) test drinking session of the DID procedure). Nor-BNI treatment significantly decreased alcohol consumption at both $2 \mathrm{hr}$ and $4 \mathrm{hr}$ time points $(* * p<0.01)$. d Decreased drinking following nor-BNI treatment resulted in a significant reduction in blood alcohol concentrations $\left({ }^{*} p<0.05\right)$
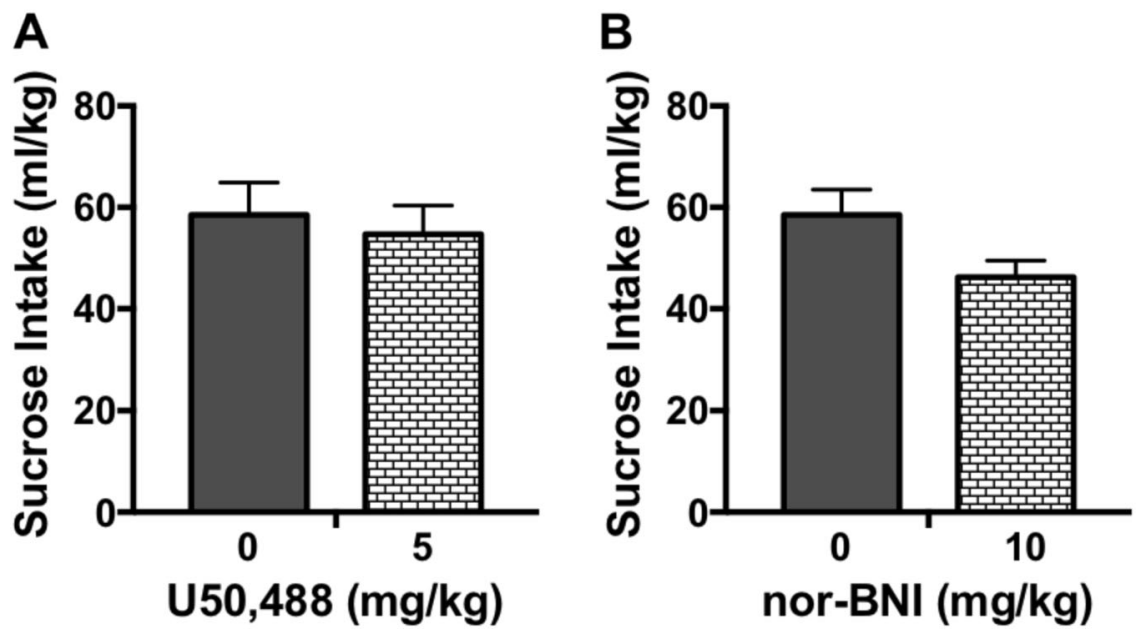

Fig. 2 Systemic administration of U50,488 or nor-BNI does not alter sucrose consumption. Mice received injection (ip.) of U50,488 (0, $5 \mathrm{mg} / \mathrm{kg})$ $(N=5-6 /$ group $)$ or nor-BNI $(0,10 \mathrm{mg} / \mathrm{kg})(\mathrm{N}=10 / \mathrm{group}) 30 \mathrm{~min}$ or $22 \mathrm{~h}$ prior to the start of the $4 \mathrm{hr}$ test drinking session of the DID procedure with $0.5 \%$ sucrose, respectively. Neither a U50,488 treatment nor b nor-BNI treatment significantly altered sucrose consumption compared to the vehicle condition

for electrophysiology recordings. Bath application of $10 \mu \mathrm{M}$ CNO resulted in a significant reduction in the membrane potential of DREADD-expressing neurons $t(7)=2.88, p<0.05$ (Fig. 4c, d). Additionally, CNO application significantly increased the rheobase of DREADD + neurons $t(7)=3.38, p<0.01$, consistent with a reduction in excitability (Fig. $4 \mathrm{e}-\mathrm{g}$ ).
Experiment 6: Chemogenetic inactivation of DYN-containing neurons in $\mathrm{CeA}$ reduces binge-like alcohol drinking

Data from two mice infused with active virus and three mice infused with control virus were excluded from analyses after histological evaluation indicated misplaced viral expression. Initial analyses indicated that order of drug treatment did not 

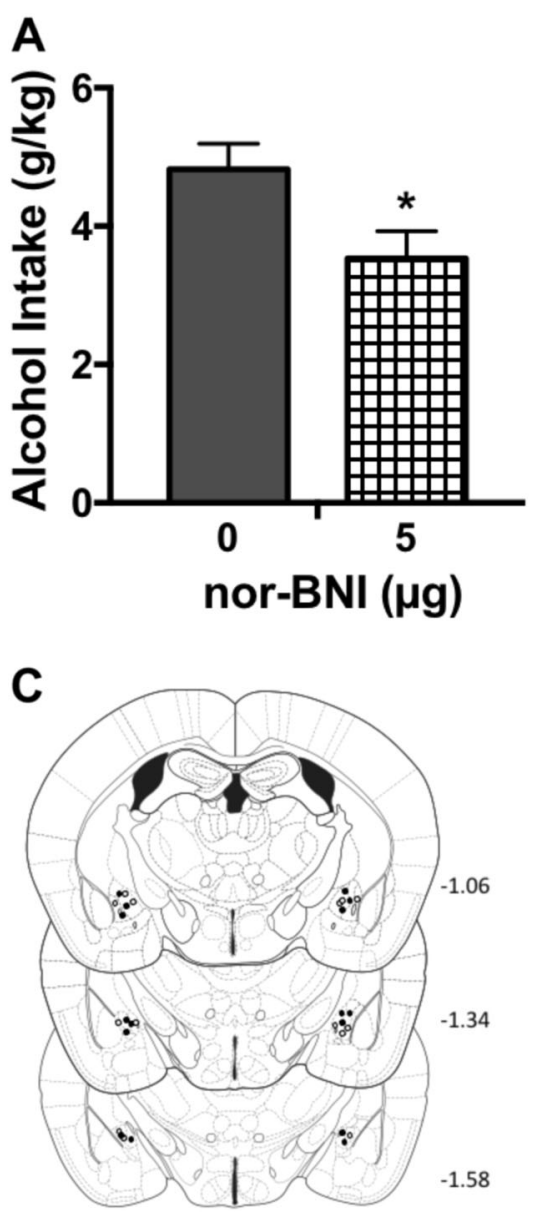

B

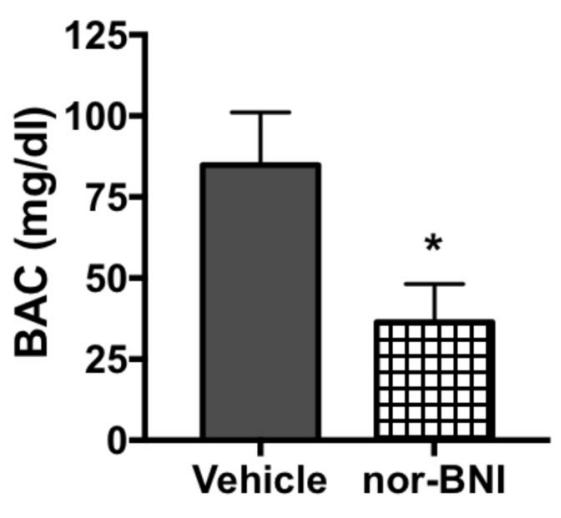

Fig. 3 Direct infusion of nor-BNI into the central amygdala (CeA) decreases binge-like alcohol consumption. Mice received intra-CeA bilateral infusion of vehicle (PBS) $(N=7)$ or nor-BNI $(2.5 \mu \mathrm{g} / \mathrm{side})(N=8) 20 \mathrm{hr}$ prior to the start of the $4 \mathrm{hr}$ test drinking session of the DID procedure. a nor-BNI treatment significantly decreased alcohol consumption $\left({ }^{*} p<0.05\right)$. b Decreased drinking following intra-CeA nor-BNI treatment resulted in a significant reduction in blood alcohol concentrations $\left({ }^{*} p<0.05\right)$. c Schematic representation of sites of vehicle (open circles) and nor-BNI (filled circles) infusions

significantly influence treatment (CNO vs. saline) effects, as indicated by nonsignificant Order $\times$ Drug $[F(1,5)=4.87, p>0.05]$ and Order $\times$ Drug $\times$ Time $[F(1,5)=2.40, p>0.10]$ interaction terms for mice injected with the hM4Di-containing virus. A similar outcome was obtained for mice injected with control virus (Order $\times$ Drug $[F(1,5)=4.62, p>0.05]$ and Order $\times$ Drug $\times$ Time $[F$ $(1,5)=0.32, p>0.50])$. Thus, data were collapsed over this variable (Order) for further analysis. Mice that received intra-CeA infusion of the inhibitory DREADD virus and injected with CNO consumed significantly less alcohol compared to the same mice that were injected with saline. This was supported by ANOVA, which revealed a significant main effect of Drug $[F(1,6)=19.85, p<$ 0.01]. Further, alcohol consumption following CNO injection was similarly reduced at 2 -hr and 4 -hr time points, as the Drug $\times$ Time interaction was not significant $[F(1,6)=1.46, p>0.10]$ (Fig. 5a). In contrast, $\mathrm{CNO}$ injection did not significantly alter alcohol intake in mice that harbored the control virus (Drug: $[F(1,6)=0.16, p>0.50]$ and Drug $\times$ Time $[F(1,6)=0.11, p>0.50]$ ) (Fig. 5b). We next examined whether systemic administration of the KOR agonist U50,488 could reverse the reduction in alcohol drinking produced by targeted chemogenetic-induced "silencing" of DYN-containing neurons in the CeA. ANOVA revealed a main effect of Treatment $[F$ $(2,12)=18.35, p<0.001]$. Post-hoc (Newman-Keuls) tests indicated that reduced drinking produced by activating the inhibitory DREADD with CNO was completely reversed when mice were pretreated with the KOR agonist U50,488 ( $p<0.001)$ (Fig. $5 c)$. Additionally, the lack of a significant Treatment $\times$ Time interaction
$[F(2,12)=2.42, p>0.10]$ indicates this effect on alcohol consumption was consistent across both the 2 -hr and 4-hr time points.

\section{DISCUSSION}

The DYN/KOR system has been implicated in various aspects of alcohol and drug addiction. A large body of evidence has established a significant role for KOR-mediated signaling in stress interactions with alcohol as well as escalated alcohol consumption associated with dependence [22, 24-26]. However, relatively little work has examined the role of the DYN/KOR system in binge-like drinking, a pattern of alcohol consumption that may promote more sustained heavy drinking and increased risk for developing alcohol use disorder $[3,4]$. Here we report that systemic activation of KOR selectively increases alcohol consumption in a binge-like drinking model whereas systemic blockade of KOR decreases alcohol intake. Further, using both pharmacological and chemogenetic approaches, we demonstrate that inhibition of DYN/KOR activity in the $\mathrm{CeA}$ significantly reduces binge-like alcohol consumption. Collectively, these results provide new information implicating a role for DYN/KOR activity within the $\mathrm{CeA}$ in regulating excessive, binge-like alcohol drinking.

In the present study, systemic administration of the KOR agonist U50,488 increased binge-like drinking while systemic administration of the relatively long-acting KOR antagonist nor-BNI, as well as the short-acting KOR antagonist LY2444296 reduced alcohol consumption. These results are generally in agreement with other 


\section{A}
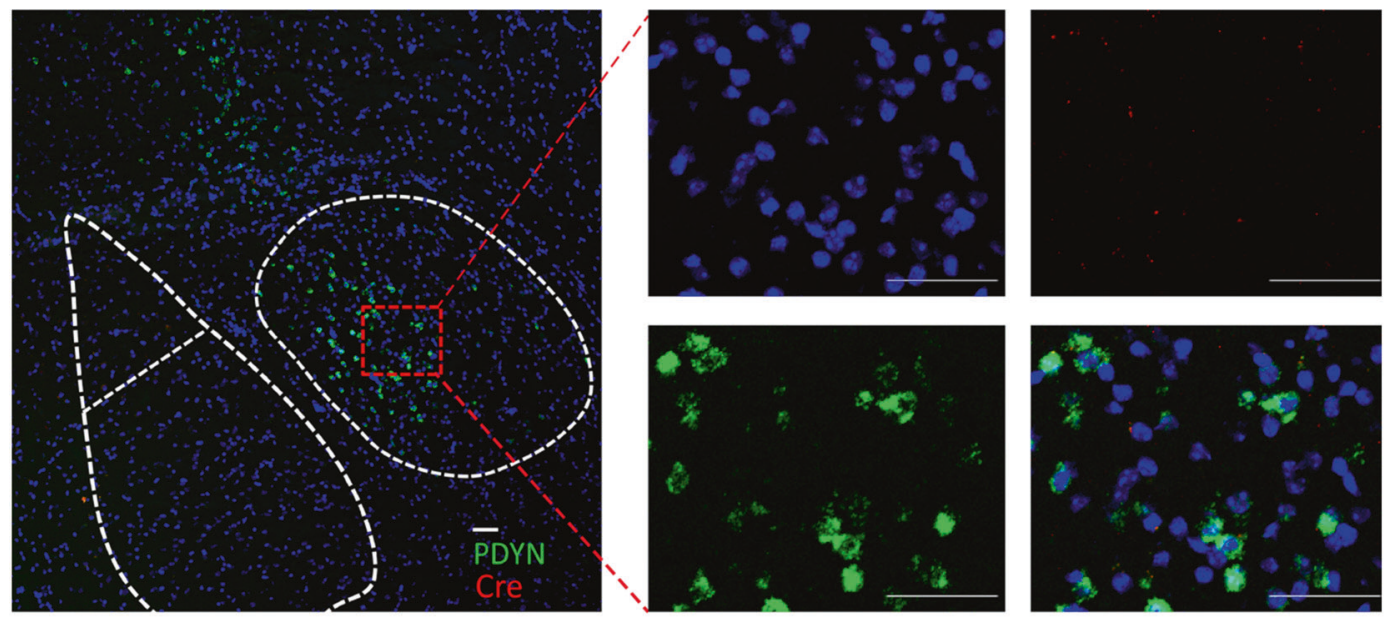

C

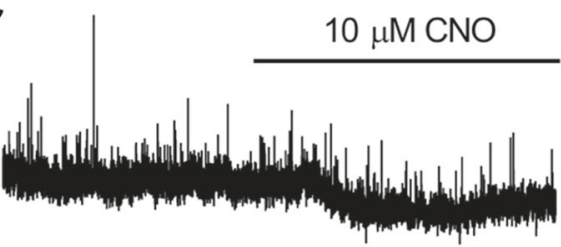

B

Cre
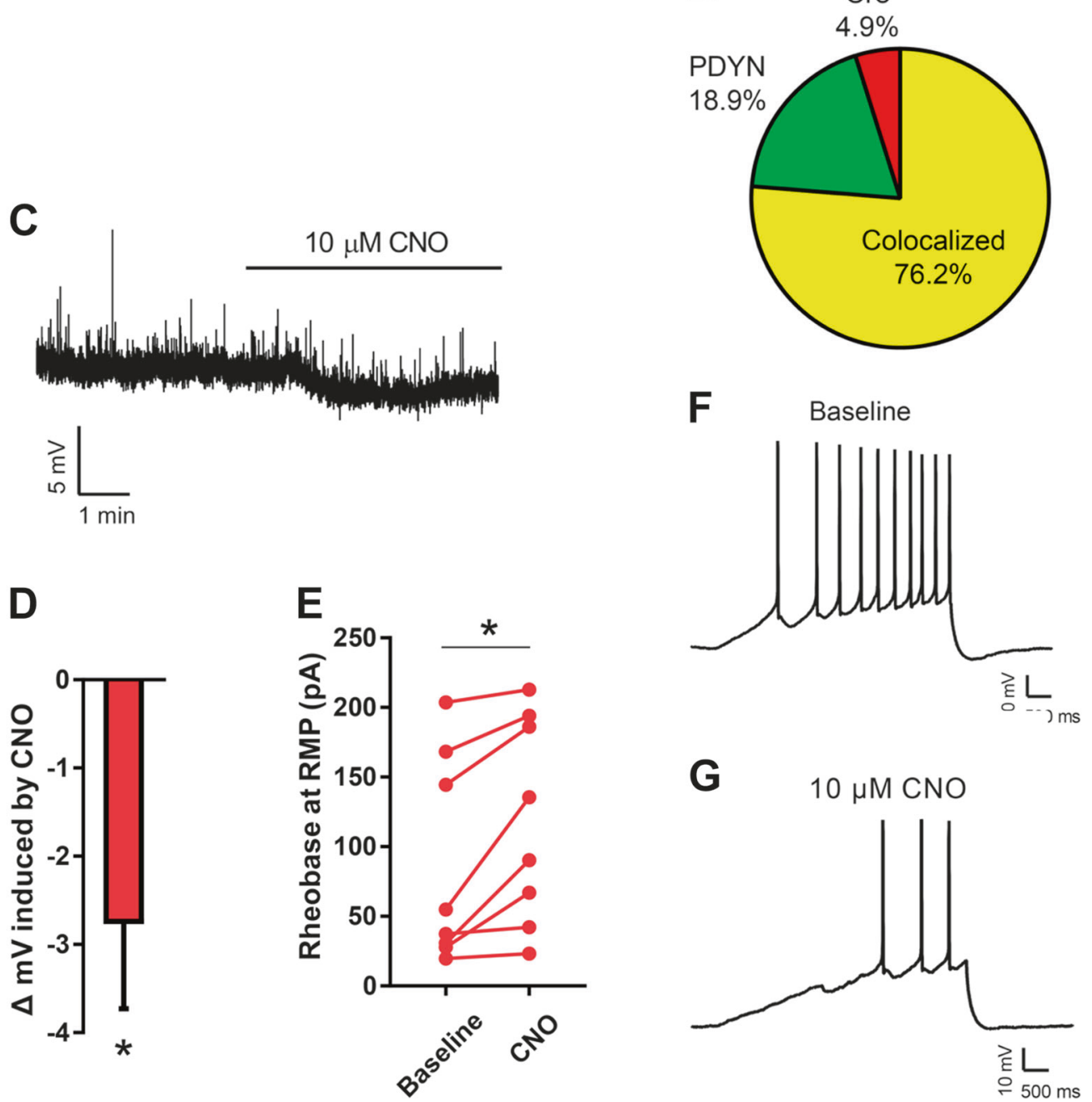

Fig. 4 Validation of genetic targeting for selective chemogenetic inactivation of dynorphin (DYN)-containing neurons. a Representative image showing in situ hybridization for Preprodynorphin and Cre in the CeA of Pdyn-Cre mice (lower right is merged image). Scale bar represents 50 microns. b Overlap of Pdyn and Cre expression from all CeA neurons counted. $\mathbf{c}$, $\mathbf{d}$ Bath application of $10 \mu \mathrm{M}$ CNO resulted in a significant hyperpolarization of mCherry positive neurons. e CNO resulted in a significant increase in the amount of current required to fire an action potential. f, $\mathbf{g}$ Representative traces showing the number of action potentials fired during a depolarizing current ramp before and after drug application 

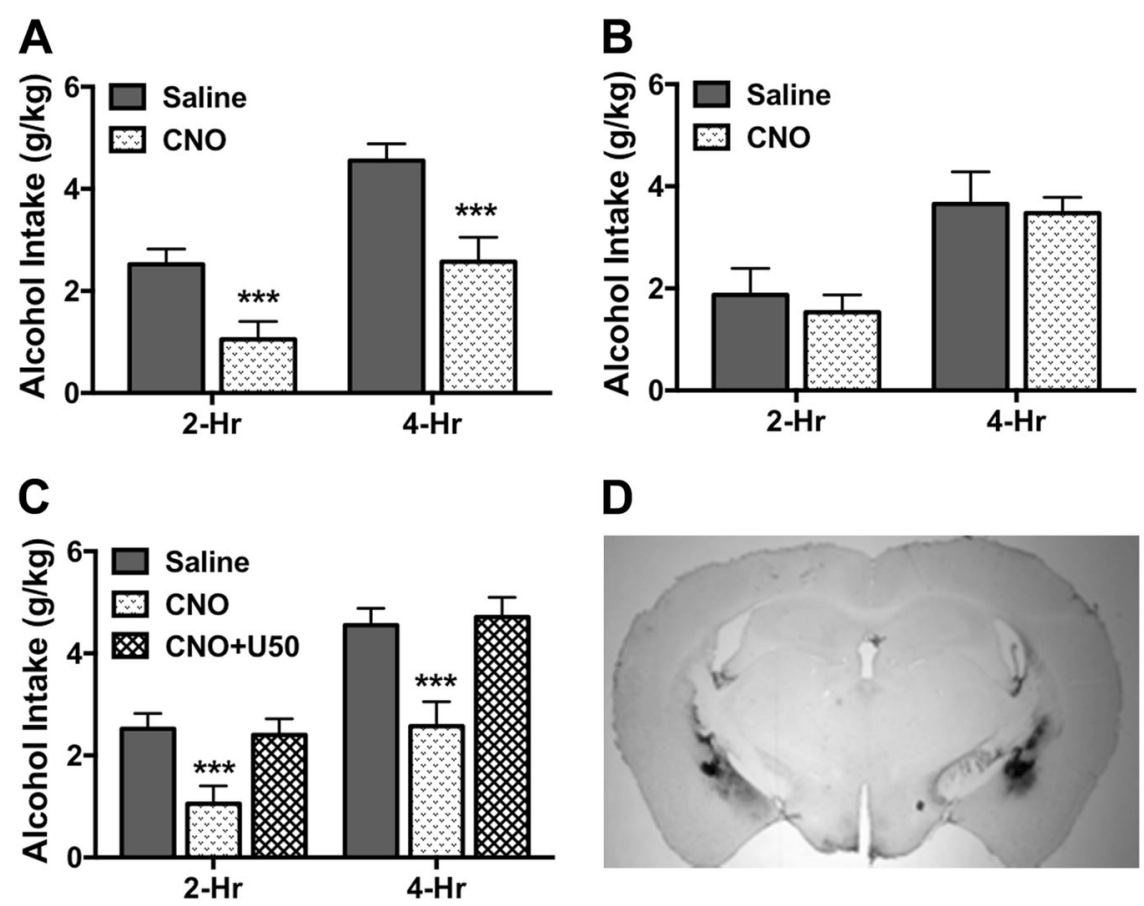

Fig. 5 Chemogenetic inactivation of DYN-containing neurons in CeA reduces binge-like alcohol drinking. a In mice treated with a virus containing an inhibitory (hM4Di) DREADD in the CeA $(N=7), \mathrm{CNO}(3 \mathrm{mg} / \mathrm{kg})$ injection significantly reduced alcohol consumption at 2-hr and 4-hr time points compared to saline injection $(* * * p<0.001)$. b In mice treated with a control virus in the CeA $(N=7)$, neither $\mathrm{CNO}(3 \mathrm{mg} / \mathrm{kg})$ nor saline injection significantly altered alcohol intake at 2-hr and 4-hr time points. c In mice harboring an inhibitory (hM4Di) DREADD in the $\mathrm{CeA}$, systemic administration of the KOR agonist U50,488 $(5 \mathrm{mg} / \mathrm{kg})$ reversed the decrease in alcohol consumption at 2-hr and 4-hr time points following CNO $(3 \mathrm{mg} / \mathrm{kg})$ injection $\left({ }^{* * *} p<0.001\right)$. d Representative viral expression in the CeA (mCherry tag visualized by colorimetric (DAB) staining)

studies in C57BL/6 J mice demonstrating increased alcohol intake after U50,488 treatment and reduced drinking following KOR antagonism [30, 33, 36]. However, a number of studies have yielded mixed results when KOR drugs are systemically administered. As recently reviewed, discrepancy of findings in this body of literature are likely due to differences in biological variables (e.g., species, strain, and sex of subjects), procedural factors (e.g., dose and timing of drug administration, and home-cage drinking vs. operant self-administration methods), and experimental variables (e.g., history of stress and alcohol exposure) [22, 24]. For example, a recent study showed that systemic administration of the KOR antagonist nor-BNI did not alter alcohol consumption during $2 \mathrm{hr}$ access in nondependent mice but did significantly reduce elevated dependence-related alcohol intake [30]. Other studies in mice $[30,33,36]$ and rats $[32,41,42]$ have shown that systemic treatment with KOR antagonists is more effective in reducing alcohol consumption that is elevated above a basal level following induction of alcohol dependence or stress exposure. The present study extends these findings to excessive levels of alcohol consumption in a binge-drinking model.

Using pharmacological and chemogenetic approaches, results from the present work provide evidence that binge-like alcohol consumption is mediated, at least in part, by DYN/KOR signaling in the CeA. There is rich expression of DYN and KOR in the CeA $[43,44]$ and the CeA is known to play an important role in bingelike drinking and alcohol consumption associated with dependence [45]. Acute alcohol administration results in DYN release in the CeA [46] and chronic alcohol vapor exposure has been shown to increase both DYN peptide expression and KOR signaling within the $\mathrm{CeA}$ [29]. In the present study, direct injection of the KOR antagonist nor-BNI into the CeA significantly reduced binge-like alcohol consumption along with associated BACs. This is in agreement with studies showing that intra-CeA administration of
nor-BNI selectively reduced elevated alcohol consumption associated with dependence in rats [29,47].

To further examine the role of DYN/KOR activity in the CeA in mediating binge-like drinking, we targeted expression of an inhibitory DREADD in DYN + neurons in the CeA. Activation of the inhibitory DREADD by systemic injection of CNO produced a significant reduction in alcohol consumption in the binge-drinking model. Importantly, the transgenic mouse model and fidelity of expression, as well as functionality of the DREADD virus were validated. Further, using a balanced design enabled demonstrating that injecting vehicle to animals that were treated with active (inhibitory DREADD) virus in the CeA did not significantly alter alcohol intake. Also, injecting CNO in animals treated with the control virus did not influence alcohol consumption, suggesting that CNO did not produce any behavioral effects in the absence of the active virus $[48,49]$. Thus, our results from pharmacological and chemogenetic approaches suggest that DYN/KOR activity in the $\mathrm{CeA}$ plays an important role in regulation of alcohol consumption, especially under conditions that engender excessive levels of intake.

While the present results indicate that the DYN/KOR system is engaged in modulating alcohol consumption in this binge-like drinking mode, the mechanism underlying this effect is not fully understood. Chemogenetic inhibition of DYN + neurons in the CeA may have reduced alcohol consumption by reducing KOR signaling locally within the $\mathrm{CeA}$ or in projection areas. Our data demonstrating that direct pharmacological blockade of KOR in the $\mathrm{Ce} A$ reduced alcohol drinking suggests that KOR signaling within the $\mathrm{CeA}$ contributes, at least in part, to the regulation of alcohol consumption. KOR have been shown to modulate alcohol-induced changes in GABA transmission in the CeA via a presynaptic and CRF-dependent manner [50,51]. However, we cannot rule out the possibility that reduced KOR activity in other brain regions (e.g., 
bed nucleus of the stria terminalis, ventral tegmental area, and nucleus accumbens) may contribute to this effect. [52, 53].

Additionally, while we effectively targeted expression of the inhibitory DREADD in DYN + neurons in the CeA, decreased alcohol consumption following the "silencing" of neuronal activity in these neurons cannot be solely attributed to reduced DYN/KOR activity. Prodynorphin-containing neurons in the $\mathrm{CeA}$ are known to co-express other peptides such as CRF [44], and altered CRF, as well as GABA release from these neurons could influence alcohol consumption $[15,45,54]$. Our results demonstrating that the KOR agonist U50,488 reversed the effects of chemogenetic inactivation of DYN + neurons in the CeA provide some support that the effects are due to reduced DYN/KOR activity in the CeA. However, since the drug was systemically administered, it cannot be ruled out that KOR activation outside the $\mathrm{CeA}$ independently mitigated effects produced by targeted chemogenetic inactivation in the $\mathrm{CeA}$. Future studies involving local KOR activation will be required to more directly address this issue.

Another issue regards the specificity of effects of manipulating DYN/KOR activity on alcohol consumption. DYN is known to play a role in food and fluid intake $[55,56]$. However, results from the present study indicated that while systemic administration of a KOR agonist $(U 50,488)$ and antagonist (LY2444296) altered alcohol consumption in the predicted manner, these drugs did not significantly influence consumption of $0.5 \%$ sucrose in the same drinking paradigm. Thus, it is unlikely that altered alcohol intake following pharmacological manipulation of KORs under the present testing conditions can be attributed to an effect on general food/fluid intake. Also, these results suggest that effects of DYN/KOR manipulation on alcohol intake do not appear to generalize to consumption of a natural reward.

Finally, it is noteworthy that while the current series of experiments were conducted using only male mice, there is some evidence indicating sex differences in sensitivity to behavioral effects of KOR drugs [57-59]. Although very few studies have examined potential sex-related differences in KOR modulation of alcohol intake, there is some evidence that female mice may be less sensitive to KOR modulation of binge-like consumption [60, 61]. Thus, this is an issue that will require further investigation as well.

In sum, results from the present study provide new evidence indicating a role for DYN/KOR system activity and, in particular, activity of this neuropeptide system within the central amygdala in regulation of binge-like alcohol drinking. These findings implicate the DYN/KOR system as a potential therapeutic target in treatment designed to reduce binge patterns of alcohol drinking, thereby impeding progression to more severe forms of alcohol addiction.

\section{FUNDING}

This work was supported by NIH grants P50 AA10716 (HCB), U01 AA014095 (HCB, MFL, WCG HLH), F32 AA023700 (RIA), T32 AA007474 (RIA), U01 AA020911 (TLK), U24 AA025475 (TLK), P60 AA011605 (TLK), and F31 AA025835 (DB), and VA grant BX000813 (HCB).

\section{ADDITIONAL INFORMATION}

Supplementary Information accompanies this paper at (https://doi.org/10.1038/ s41386-018-0294-3).

Competing interests: The authors declare no competing interests.

Publisher's note: Springer Nature remains neutral with regard to jurisdictional claims in published maps and institutional affiliations.

\section{REFERENCES}

1. Centers for Disease Control, Prevention. Vital signs: binge drinking prevalence, frequency, and intensity among adults-United States, 2010. MMWR Morb Mortal Wkly Rep. 2012;61:14-9.
2. NIAAA NIoAAaA. National Institute on Alcohol Abuse and Alcoholism Council approves definition of binge drinking. NIAAA Newsl. 2004;3:3.

3. Jennison KM. The short-term effects and unintended long-term consequences of binge drinking in college: a 10-year follow-up study. Am J Drug Alcohol Abus. 2004;30:659-84.

4. McCarty CA, Ebel BE, Garrison MM, DiGiuseppe DL, Christakis DA, Rivara FP. Continuity of binge and harmful drinking from late adolescence to early adulthood. Pediatrics . 2004;114:714-9. https://doi.org/10.1542/peds.2003-0864-L

5. Koob GF. Neurocircuitry of alcohol addiction: synthesis from animal models. Handb Clin Neurol. 2014;125:33-54. https://doi.org/10.1016/B978-0-444-626196.00003-3

6. Koob GF, Volkow ND. Neurobiology of addiction: a neurocircuitry analysis. Lancet Psychiatry. 2016;3:760-73. https://doi.org/10.1016/S2215-0366(16)00104-8

7. Crabbe JC, Harris RA, Koob GF. Preclinical studies of alcohol binge drinking. Ann N Y Acad Sci. 2011;1216:24-40. https://doi.org/10.1111/j.1749-6632.2010.05895.x

8. Rhodes JS, Best K, Belknap JK, Finn DA, Crabbe JC. Evaluation of a simple model of ethanol drinking to intoxication in C57BL/6J mice. Physiol Behav. 2005;84:53-63. https://doi.org/10.1016/j.physbeh.2004.10.007

9. Thiele TE, Crabbe JC, Boehm SL II. "Drinking in the Dark" (DID): a simple mouse model of binge-like alcohol intake. Curr Protoc Neurosci. 2014;68:9 49 1-12. https://doi.org/10.1002/0471142301.ns0949s68

10. Thiele TE, Navarro M. "Drinking in the dark" (DID) procedures: a model of bingelike ethanol drinking in non-dependent mice. Alcohol . 2014;48:235-41. https:// doi.org/10.1016/j.alcohol.2013.08.005

11. Rhodes JS, Ford MM, Yu CH, Brown LL, Finn DA, Garland T Jr., et al. Mouse inbred strain differences in ethanol drinking to intoxication. Genes Brain Behav. 2007;6:1-18. https://doi.org/10.1111/j.1601-183X.2006.00210.x

12. Crabbe JC, Metten P, Rhodes JS, Yu CH, Brown LL, Phillips TJ, et al. A line of mice selected for high blood ethanol concentrations shows drinking in the dark to intoxication. Biol Psychiatry. 2009;65:662-70. https://doi.org/10.1016/j. biopsych.2008.11.002

13. Sprow GM, Thiele TE. The neurobiology of binge-like ethanol drinking: evidence from rodent models. Physiol Behav. 2012;106:325-31. https://doi.org/10.1016/j. physbeh.2011.12.026

14. Lowery EG, Spanos M, Navarro M, Lyons AM, Hodge CW, Thiele TE. CRF-1 antagonist and CRF-2 agonist decrease binge-like ethanol drinking in C57BL/6J mice independent of the HPA axis. Neuropsychopharmacology 2010;35:1241-52. https://doi.org/10.1038/npp.2009.209

15. Lowery-Gionta EG, Navarro M, Li C, Pleil KE, Rinker JA, Cox BR, et al. Corticotropin releasing factor signaling in the central amygdala is recruited during binge-like ethanol consumption in C57BL/6J mice. J Neurosci. 2012;32:3405-13. https://doi. org/10.1523/JNEUROSCI.6256-11.2012

16. Rinker JA, Marshall SA, Mazzone CM, Lowery-Gionta EG, Gulati V, Pleil KE, et al. Extended amygdala to ventral tegmental area corticotropin-releasing factor circuit controls binge ethanol intake. Biol Psychiatry. 2017;81:930-40. https://doi. org/10.1016/j.biopsych.2016.02.029

17. Pleil KE, Rinker JA, Lowery-Gionta EG, Mazzone CM, McCall NM, Kendra AM, et al. NPY signaling inhibits extended amygdala CRF neurons to suppress binge alcohol drinking. Nat Neurosci. 2015;18:545-52. https://doi.org/10.1038/ nn.3972

18. Sparrow AM, Lowery-Gionta EG, Pleil KE, Li C, Sprow GM, Cox BR, et al. Central neuropeptide $Y$ modulates binge-like ethanol drinking in $C 57 \mathrm{BL} / 6 \mathrm{~J}$ mice via $\mathrm{Y} 1$ and $Y 2$ receptors. Neuropsychopharmacology . 2012;37:1409-21. https://doi.org/ 10.1038/npp.2011.327

19. Anderson $\mathrm{Rl}$, Becker $\mathrm{HC}$, Adams BL, Jesudason $\mathrm{CD}$, Rorick-Kehn LM. Orexin-1 and orexin-2 receptor antagonists reduce ethanol self-administration in high-drinking rodent models. Front Neurosci. 2014;8:33 https://doi.org/10.3389/fnins.2014.00033

20. Olney JJ, Navarro M, Thiele TE. Binge-like consumption of ethanol and other salient reinforcers is blocked by orexin-1 receptor inhibition and leads to a reduction of hypothalamic orexin immunoreactivity. Alcohol Clin Exp Res. 2015;39:21-9. https://doi.org/10.1111/acer.12591

21. King CE, Griffin WC, Luderman LN, Kates MM, McGinty JF, Becker HC. Oxytocin reduces ethanol self-administration in mice. Alcohol Clin Exp Res. 2017;41:955-64. https://doi.org/10.1111/acer.13359

22. Anderson Rl, Becker HC. Role of the dynorphin/kappa opioid receptor system in the motivational effects of ethanol. Alcohol Clin Exp Res. 2017;41:1402-18. https://doi.org/10.1111/acer.13406

23. Chavkin C. Dynorphin-still an extraordinarily potent opioid peptide. Mol Pharmacol. 2013;83:729-36. https://doi.org/10.1124/mol.112.083337

24. Anderson RI, Moorman DE, Becker HC. Contribution of Dynorphin and Orexin Neuropeptide Systems to the Motivational Effects of Alcohol. Handb Exp Pharmacol. 2018. https://doi.org/10.1007/164_2018_100

25. Bruchas MR, Land BB, Chavkin C. The dynorphin/kappa opioid system as a modulator of stress-induced and pro-addictive behaviors. Brain Res. 2010;1314:44-55. https://doi.org/10.1016/j.brainres.2009.08.062 
26. Crowley NA, Kash TL. Kappa opioid receptor signaling in the brain: circuitry and implications for treatment. Prog Neuropsychopharmacol Biol Psychiatry. 2015;62:51-60. https://doi.org/10.1016/j.pnpbp.2015.01.001

27. Wee S, Koob GF. The role of the dynorphin-kappa opioid system in the reinforcing effects of drugs of abuse. Psychopharmacol (Berl). 2010;210:121-35. https:// doi.org/10.1007/s00213-010-1825-8

28. Berger AL, Williams AM, McGinnis MM, Walker BM. Affective cue-induced escalation of alcohol self-administration and increased $22-\mathrm{kHz}$ ultrasonic vocalizations during alcohol withdrawal: role of kappa-opioid receptors. Neuropsychopharmacology . 2013;38:647-54. https://doi.org/10.1038/npp.2012.229

29. Kissler JL, Sirohi S, Reis DJ, Jansen HT, Quock RM, Smith DG, et al. The one-two punch of alcoholism: role of central amygdala dynorphins/kappa-opioid receptors. Biol Psychiatry. 2014;75:774-82. https://doi.org/10.1016/j.biopsych.2013.03.014

30. Rose JH, Karkhanis AN, Chen R, Gioia D, Lopez MF, Becker HC et al. Supersensitive Kappa Opioid Receptors Promotes Ethanol Withdrawal-Related Behaviors and Reduce Dopamine Signaling in the Nucleus Accumbens. Int J Neuropsychopharmacol. 2016;19. https://doi.org/10.1093/ijnp/pyv127

31. Walker BM, Koob GF. Pharmacological evidence for a motivational role of kappa-opioid systems in ethanol dependence. Neuropsychopharmacology . 2008;33:643-52. https://doi.org/10.1038/sj.npp.1301438

32. Walker BM, Zorrilla EP, Koob GF. Systemic kappa-opioid receptor antagonism by nor-binaltorphimine reduces dependence-induced excessive alcohol selfadministration in rats. Addict Biol. 2011;16:116-9. https://doi.org/10.1111/ j.1369-1600.2010.00226.x

33. Anderson Rl, Lopez MF, Becker HC. Stress-induced enhancement of ethanol intake in c57bl/6j mice with a history of chronic ethanol exposure: involvement of kappa opioid receptors. Front Cell Neurosci. 2016;10:45 https://doi.org/ 10.3389/fncel.2016.00045

34. Karkhanis AN, Rose JH, Weiner JL, Jones SR. Early-life social isolation stress increases kappa opioid receptor responsiveness and downregulates the dopamine system. Neuropsychopharmacology . 2016;41:2263-74. https://doi.org/ 10.1038/npp.2016.21

35. Racz I, Markert A, Mauer D, Stoffel-Wagner B, Zimmer A. Long-term ethanol effects on acute stress responses: modulation by dynorphin. Addict Biol. 2013;18:678-88. https://doi.org/10.1111/j.1369-1600.2012.00494.x

36. Sperling RE, Gomes SM, Sypek El, Carey AN, McLaughlin JP. Endogenous kappaopioid mediation of stress-induced potentiation of ethanol-conditioned place preference and self-administration. Psychopharmacol (Berl). 2010;210:199-209. https://doi.org/10.1007/s00213-010-1844-5

37. Krashes MJ, Shah BP, Madara JC, Olson DP, Strochlic DE, Garfield AS, et al. An excitatory paraventricular nucleus to AgRP neuron circuit that drives hunger. Nature . 2014:507:238-42. https://doi.org/10.1038/nature12956

38. Mitch CH, Quimby SJ, Diaz N, Pedregal C, de la Torre MG, Jimenez A, et al. Discovery of aminobenzyloxyarylamides as kappa opioid receptor selective antagonists: application to preclinical development of a kappa opioid receptor antagonist receptor occupancy tracer. J Med Chem. 2011;54:8000-12. https://doi. org/10.1021/jm200789r

39. Melief EJ, Miyatake M, Carroll Fl, Beguin C, Carlezon WA Jr., Cohen BM, et al. Duration of action of a broad range of selective kappa-opioid receptor antagonists is positively correlated with c-Jun N-terminal kinase-1 activation. Mol Pharmacol. 2011;80:920-9. https://doi.org/10.1124/mol.111.074195

40. Armbruster BN, Li X, Pausch MH, Herlitze S, Roth BL. Evolving the lock to fit the key to create a family of $\mathrm{G}$ protein-coupled receptors potently activated by an inert ligand. Proc Natl Acad Sci USA. 2007;104:5163-8. https://doi.org/10.1073/ pnas.0700293104

41. Schank JR, Goldstein AL, Rowe KE, King CE, Marusich JA, Wiley JL, et al. The kappa opioid receptor antagonist JDTic attenuates alcohol seeking and withdrawal anxiety. Addict Biol. 2012;17:634-47. https://doi.org/10.1111/j.1369-1600.2012.00455.x

42. Domi E, Barbier E, Augier E, Augier G, Gehlert D, Barchiesi R, et al. Preclinical evaluation of the kappa-opioid receptor antagonist CERC-501 as a candidate therapeutic for alcohol use disorders. Neuropsychopharmacology. 2018; 43:1805-12. https://doi.org/10.1038/s41386-018-0015-y

43. Mansour A, Fox CA, Meng F, Akil H, Watson SJ. Kappa 1 receptor mRNA distribution in the rat CNS: comparison to kappa receptor binding and prodynorphin mRNA. Mol Cell Neurosci. 1994;5:124-44. https://doi.org/10.1006/ mone.1994.1015
44. Marchant NJ, Densmore VS, Osborne PB. Coexpression of prodynorphin and corticotrophin-releasing hormone in the rat central amygdala: evidence of two distinct endogenous opioid systems in the lateral division. J Comp Neurol. 2007;504:702-15. https://doi.org/10.1002/cne.21464

45. Gilpin NW, Herman MA, Roberto M. The central amygdala as an integrative hub for anxiety and alcohol use disorders. Biol Psychiatry. 2015;77:859-69. https://doi. org/10.1016/j.biopsych.2014.09.008

46. Lam MP, Marinelli PW, Bai L, Gianoulakis C. Effects of acute ethanol on opioid peptide release in the central amygdala: an in vivo microdialysis study. Psychopharmacol (Berl). 2008;201:261-71. https://doi.org/10.1007/s00213-0081267-8

47. Kissler JL, Walker BM. Dissociating motivational from physiological withdrawal in alcohol dependence: role of central amygdala kappa-opioid receptors. Neuropsychopharmacology . 2016;41:560-7. https://doi.org/10.1038/npp.2015.183

48. Gomez JL, Bonaventura J, Lesniak W, Mathews WB, Sysa-Shah P, Rodriguez LA, et al. Chemogenetics revealed: DREADD occupancy and activation via converted clozapine. Science . 2017;357:503-7. https://doi.org/10.1126/science. aan2475

49. Manvich DF, Webster KA, Foster SL, Farrell MS, Ritchie JC, Porter JH, et al. The DREADD agonist clozapine $\mathrm{N}$-oxide (CNO) is reverse-metabolized to clozapine and produces clozapine-like interoceptive stimulus effects in rats and mice. Sci Rep. 2018;8:3840 https://doi.org/10.1038/s41598-018-22116-z

50. Kang-Park M, Kieffer BL, Roberts AJ, Siggins GR, Moore SD. kappa-Opioid receptors in the central amygdala regulate ethanol actions at presynaptic GABAergic sites. J Pharmacol Exp Ther. 2013;346:130-7. https://doi.org/10.1124/ jpet.112.202903

51. Kang-Park M, Kieffer BL, Roberts AJ, Siggins GR, Moore SD. Interaction of CRF and kappa opioid systems on GABAergic neurotransmission in the mouse central amygdala. J Pharmacol Exp Ther. 2015;355:206-11. https://doi.org/10.1124/ jpet.115.225870

52. Li C, Pleil KE, Stamatakis AM, Busan S, Vong L, Lowell BB, et al. Presynaptic inhibition of gamma-aminobutyric acid release in the bed nucleus of the stria terminalis by kappa opioid receptor signaling. Biol Psychiatry. 2012;71:725-32. https://doi.org/10.1016/j.biopsych.2011.11.015

53. Stamatakis AM, Sparta DR, Jennings JH, McElligott ZA, Decot $H$, Stuber GD. Amygdala and bed nucleus of the stria terminalis circuitry: implications for addiction-related behaviors. Neuropharmacology . 2014;76:320-8. https://doi. org/10.1016/j.neuropharm.2013.05.046

54. Roberto M, Cruz MT, Gilpin NW, Sabino V, Schweitzer P, Bajo M, et al. Corticotropin releasing factor-induced amygdala gamma-aminobutyric acid release plays a key role in alcohol dependence. Biol Psychiatry. 2010;67:831-9. https:// doi.org/10.1016/j.biopsych.2009.11.007

55. Beczkowska IW, Bowen WD, Bodnar RJ. Central opioid receptor subtype antagonists differentially alter sucrose and deprivation-induced water intake in rats. Brain Res. 1992;589:291-301.

56. Morley JE, Levine AS. Involvement of dynorphin and the kappa opioid receptor in feeding. Peptides . 1983;4:797-800.

57. Chartoff EH, Mavrikaki M. Sex differences in kappa opioid receptor function and their potential impact on addiction. Front Neurosci. 2015;9:466 https://doi.org/ 10.3389/fnins.2015.00466

58. Robles CF, McMackin MZ, Campi KL, Doig IE, Takahashi EY, Pride MC, et al. Effects of kappa opioid receptors on conditioned place aversion and social interaction in males and females. Behav Brain Res. 2014;262:84-93. https://doi.org/10.1016/j. bbr.2014.01.003

59. Russell SE, Rachlin AB, Smith KL, Muschamp J, Berry L, Zhao Z, et al. Sex differences in sensitivity to the depressive-like effects of the kappa opioid receptor agonist U-50488 in rats. Biol Psychiatry. 2014;76:213-22. https://doi.org/10.1016/j. biopsych.2013.07.042

60. Van't Veer A, Smith KL, Cohen BM, Carlezon WA Jr., Bechtholt AJ. Kappa-opioid receptors differentially regulate low and high levels of ethanol intake in female mice. Brain Behav. 2016;6:e00523 https://doi.org/10.1002/brb3.523

61. Zhou Y, Crowley RS, Ben K, Prisinzano TE, Kreek MJ. Synergistic blockade of alcohol escalation drinking in mice by a combination of novel kappa opioid receptor agonist Mesyl Salvinorin B and naltrexone. Brain Res. 2017;1662:75-86. https://doi.org/10.1016/j.brainres.2017.02.027 